\title{
記録・再生等化とビタビ復号法による 誤り率特性の改善
}

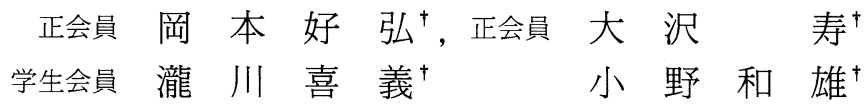

\section{Improvement of Error Rate Performance by Write and Read Equalization and Viterbi Decoding}

\author{
Yoshihiro Okamoto $^{\dagger}$, Hisashi Ohosawa ${ }^{\dagger}$, \\ Kiyoshi Takigawa ${ }^{\dagger}$ and Kazuo $\mathrm{Ono}^{\dagger}$
}

\begin{abstract}
DC freeing of the write waveform is an important technique in digital magnetic recording. The higher the recording density is, the stronger the effect of high frequency noise becomes. We use the DC-freeing technique of write equalization to boost high frequency on the write side, and read equalization with which we can reduce high-frequency noise with little degradation of the eye opening, is adopted on the read side. In addition, we adopt Viterbi decoding as a decoding method for further improvement. In this paper, we report the synthesis of this write and read equalization method. Computer simulation shows that our system has an excellent error rate performance compared with the well-known combination of NRZ recording code and integrated detection.
\end{abstract}

\section{1. まえ がき}

近年のディジタル磁気記録における記録密度の向上 にはめざましいものがあり ${ }^{122)}$, 高密度化に対して信 号処理の担うところも次第に大となっている.なかで も記録符号，パーシャルレスポンス方式，ビタビ復号 法等の信号処理方式に対する期待はとみに高まってい $3^{3) \sim 5)}$

最近提案された興味ある信号処理方式として，記録
波形にパルスを付加することにより，ディジタル記録 に適した波形を得るような記録等化方式がある677). また筆者らは, この記録等化器と, 信号検出時に高域 ノイズを抑圧でき，しかもアイ開口の劣化が小である ような再生等化方式㧍よび新たな信号検出方式とを組 合せた記録・再生等化方式を提案し，良好な誤り率特 性が得られることを明らかにしている8.

本論文では，このような記録・再生等化方式にビ夕 ビ復号法を適用した場合の誤り率特性を計算機シミュ

キーワード：ディジタル磁気記録, 信号処理, 記録等化, ビタビ復号法

1991 年 7 月 23 日, 1991 年テレビジョン学会年次大会で発表

1992 年 2 月 26 日受付, 1992 年 4 月 27 日再受付

†愛媛大学 工学部電気電子工学科 ( 790 松山市文京町 3, TEL 0899-24-7111)

$\dagger$ Faculty of Engineering, Ehime University (3, Bunkyocho, Matsuyama-shi, Ehime 790, Japan) 
レーションにより求め, 従来から優れた特性を示すこ とでよく知られている NRZ 符号に対する積分検出方 式9)と比較検討する.

\section{2. 記録・再生系モデル}

図 1 亿, 記録・再生等化器を含む記録再生系のブロ ック図を示す. $\left\{a_{k}\right\}$ は“1”, “0”の 2 值入力デー夕系 列で, 図 2 に示す記録等化器により記録等化が施さ れ，2 值記録が行われる。この記録等化器は, 再生等 化器に適した記録波形を生成できるように, 文献 6) の記録等化器の付加パルス生成側に(1) 式に示す遅延 演算子 $D$ を挿入した構成となっている.

$$
D=e^{-j \omega T_{b} / 2}
$$

ここに $T_{b}$ はビット間隔である. 図 3 に記録等化器入 出力波形を示す．ここで, 記録等化器入力波形 ( a ) は 入力デー夕系列 $\left\{a_{k}\right\}$ に対するNRZI 波形で, これに 網掛部で示されるようなパルスを付加することで, $\mathrm{DC}$ フリーな記録波形 $(\mathrm{b})$ を得ることができる ${ }^{8)}$.ま た，この記録等化方式に対するビットセル単位の記録 波形は表 1 に示す 4 種類のみで，これをそれぞれ状態 $S_{0}, S_{1}, S_{2}, S_{3}$ とする.

読出し点における雑音を, 両側電力スペクトル密度

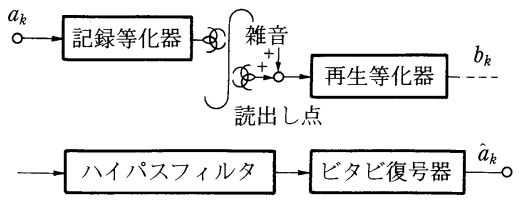

図 1 記録・再生系のブロック図 Block diagram of write and read system.

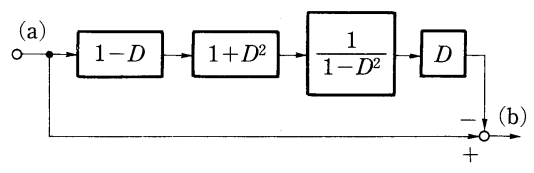

図 2 記録等化器のブロック図 Black diagram of write equalizer.
が $N_{0} / 2$ で, 平均值が 0 の白色ガウス雑音とし, 孤立 再生波形を次式で与えられるローレンツ形と仮定す る.

$$
h(t)=A /\left\{1+\left(2 t / T_{50}\right)^{2}\right\}
$$

ここに, $A$ はピーク值, $T_{50}$ は半值幅である. 高さが 1 , 幅が $T_{b}$ の記録波形に対する再生等化器入力は,

$$
g(t)=\frac{1}{2}\left\{h(t)-h\left(t-T_{b}\right)\right\}
$$

となり,これに対する再生等化器出力が,

$$
w(t)=r\left(t-\frac{T_{b}}{2}\right)
$$

となるように再生等化器の伝達特性を定めるものとす る.ここで $r(t)$ はロールオフ率 $\beta$ のナイキスト波形 で,

$$
r(t)=\frac{\sin \left(\pi t / \eta T_{b}\right)}{\pi t / \eta T_{b}} \cdot \frac{\cos \left(\pi \beta t / \eta T_{b}\right)}{1-\left(2 \beta t / \eta T_{b}\right)^{2}}
$$

で与えられる。ただし， $\eta$ は再生等化器の帯域幅と波 形干渉を調整するためのパラメータである.

入力デー夕系列 $\left\{a_{k}\right\}$ に対する再生等化器出力波形 $y(t)$ は,

$$
y(t)=\sum_{i} L_{i}\left\{a_{i} w_{1}\left(t-i T_{b}\right)+\left(1-a_{i}\right) w_{o}\left(t-i T_{b}\right)\right\}
$$

で表される。ここに $L_{i}$ は図 2 の入力 (a)における NRZI 波形レベルで \pm 1 なる值を取り, 次式により与 えられる。

$$
L_{i}=\left(1-2 a_{i}\right) L_{i-1}
$$

また，

$$
\begin{aligned}
& w_{1}(t)=w_{h}(t)+w_{h}\left(t-\frac{T_{b}}{2}\right) \\
& w_{0}(t)=w_{h}(t)-w_{h}\left(t-\frac{T_{b}}{2}\right)
\end{aligned}
$$

である、ただし, $w_{h}(t)$ は高さが 1 , 幅が $T_{b} / 2$ の記 録波形に対する再生等化器入力波形,

$$
g_{h}(t)=\frac{1}{2}\left\{h(t)-h\left(t-\frac{T_{b}}{2}\right)\right\}
$$

の応答波形で,

$w_{h}(t)=\int_{0}^{(1+\beta) / 2 \eta} R(x) \frac{1}{\cos \frac{\pi x}{2}} \cos 2 \pi\left(\frac{t}{T_{b}}-\frac{1}{4}\right) x d x$

表 1 記録等化に対する記録波形と状態 Write waveforms and states for write equalization.

\begin{tabular}{c|c|c|c|c}
\hline \hline 状態 & $S_{0}$ & $S_{1}$ & $S_{2}$ & $S_{3}$ \\
\hline $\begin{array}{c}\text { 記録 } \\
\text { 波形 }\end{array}$ & - & & $\square$ & $\sqrt{ }$ \\
\hline$a_{k}$ & 1 & 1 & 0 & 0 \\
\hline
\end{tabular}

(19) 1235 
で与えられる。ここに $R(x)$ は $f_{b} r(t)$ のフーリエ変 換で,

$$
R(x)=\left\{\begin{array}{lr}
\eta, & |x|<\frac{1-\beta}{2 \eta} \\
\frac{\eta}{2}\left\{1-\sin \frac{\eta x}{\beta}\left(|x|-\frac{1}{2 \eta}\right)\right\}, \frac{1-\beta}{2 \eta} \leq & |x|<\frac{1+\beta}{2 \eta} \\
0, & |x| \geq \frac{1+\beta}{2 \eta}
\end{array}\right.
$$

である。

$t=k T_{b}$ における $y(t)$ のサンプル值を再生等化器出 力系列を $b_{k}$ とすると, (6)式より,

$$
\begin{aligned}
b_{k} & =y\left(k T_{b}\right) \\
& =\sum_{i} L_{i}\left[a_{i} w_{1}\left\{(k-i) T_{b}\right\}+\left(1-a_{i}\right) w_{0}\left\{(k-i) T_{b}\right\}\right]
\end{aligned}
$$

となる。

\section{3. 識別点雑音電力}

再生等化器の伝達関数 $E_{r}(x)$ は ( 3$)$ 式と $(4)$ 式の フーリエ変換の比を取ることにより得られ，

$$
E_{r}(x)=\frac{2}{j A K \pi} \cdot \frac{1}{\sin \pi x} R(x) e^{\pi K|x|}
$$

となる．ここで $K=T_{50} / T_{b}$ は規格化線密度である. (14) 式から明らかなように, 再生等化器出力における 雑音電力スペクトルは低域強調型となる。そこで, 低 域に扔ける過度の雑音増加を抑圧するため, 図 1 亿示 すようなハイパスフィル夕により低域遮断を行う必要 がある. 遮断周波数が $f_{c}=1 /(2 \pi R C)$ の RC八イパス フィルタにより低域遮断を行うものとすると, その伝 達関数は,

$$
Q(x)=\frac{j x / x_{c}}{1+j x / x_{c}}
$$

となる.ここに $x_{c}=f_{c} / f_{b}$ は規格化遮断周波数であ る.

識別点の雑音電力は $N_{0}\left|E_{r}(x) Q(x)\right|^{2} / 2$ を積分する ことにより得られ，

$$
\sigma^{2}=\int_{0}^{(1+\beta) / 2 \eta} N(x) d x
$$

となる。ただし， $N(x)$ は識別点における片側雑音電 カスペクトル密度で,

$$
N(x)=\frac{4}{\pi^{2} \alpha^{2} K^{2}} \cdot \frac{1}{\sin ^{2} \pi x} R^{2}(x) e^{2 \pi K x} \frac{x^{2}}{x^{2}+x_{c}^{2}}
$$

である.ここで, $a$ は次式で定義される読出し点の $\mathrm{SN}$ 比である.

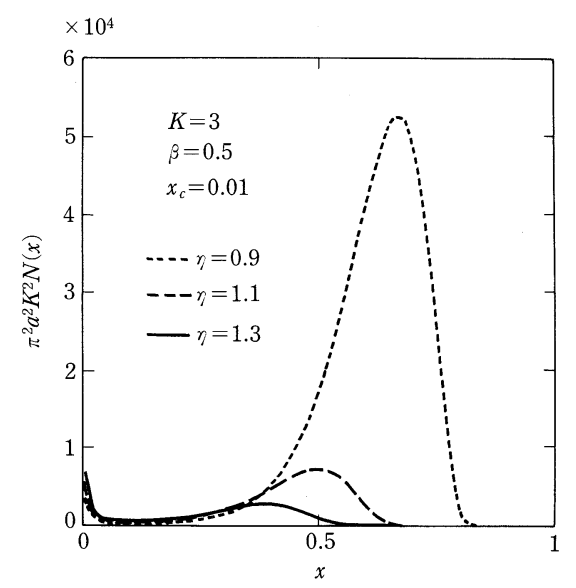

図 4 識別点雑音電力スペクトル Power spectra of noise at the discrimination point.

$$
a=A / \sqrt{N_{0} f_{b}}
$$

図 4 に(17)式から求めた識別点の雑音電力スペクト ルを示す。ただし, 文献 10)においてディジタル VTRにおける $K$ の実測值の占める值として $K=2.5$ 〜3が報告されており, ここでは, そのうちの最大值 である $K=3$ とし $, \beta=0.5, x_{c}=0.01^{11)}$ としている. 図より, $\eta$ を大きくすると再生等化器の帯域幅が狭く なり雑音電力が減少することがわかる。

\section{4. 識別点信号波形}

3 章で述べたように, 低域での過度の雑音増加を抑 圧するために挿入した RCハイパスフィルタにより再 生等化器出力波形は低域遮断の影響を受ける。したが って, 識別点信号波形は (6) 式より,

$$
\begin{aligned}
\widetilde{y}(t) & =y(t) * q(t) \\
& =\sum_{i} L_{i}\left\{a_{i} \tilde{w}_{1}\left(t-i T_{b}\right)+\left(1-a_{i}\right) \tilde{w}_{0}\left(t-i T_{b}\right)\right\}
\end{aligned}
$$

となる。ここに*は畳み込み積分を表し,$q(t)$ は RC ハイパスフィルタのインパルス応答である.ここで,

$$
\begin{aligned}
& \widetilde{w}_{1}(t)=\widetilde{w}_{h}(t)+\widetilde{w}_{h}\left(t-\frac{T_{b}}{2}\right) \\
& \widetilde{w}_{0}(t)=\widetilde{w}_{h}(t)-\widetilde{w}_{h}\left(t-\frac{T_{b}}{2}\right)
\end{aligned}
$$

である.また, $\widetilde{w}_{h}(t)$ は高さが 1, 幅が $T_{b} / 2$ の記録 波形に対するハイパスフィルタの出力波形で, 次のよ うに $w_{h}(t)$ と $q(t)$ の畳み込み積分により与えられ る. 


$$
\begin{aligned}
\tilde{w}_{h}(t)= & w_{h}(t) * q(t) \\
= & \int_{0}^{(1+\beta) / 2 \eta} \frac{1}{\cos \frac{\pi x}{2}} R(x) \\
& \cdot\left(\frac{x}{x_{c}}\right)^{2} \cos 2 \pi\left(\frac{t}{T_{b}}-\frac{1}{4}\right) x \\
& \cdot \frac{-\frac{x}{x_{c}} \sin 2 \pi\left(\frac{t}{T_{b}}-\frac{1}{4}\right) x}{1+\left(\frac{x}{x_{c}}\right)^{2}} d x
\end{aligned}
$$

$\mathrm{M}$ 系列を用いて発生した 1000 ビットの入力デー夕系 列 $\left\{a_{k}\right\}$ を(19)式に適用して求めた $\eta=1.3$ に対するア イパターンを図5に示す。ただし， $\beta=0.5, x_{c}=0.01$ としている.図に見られるように， $\eta=0.9$ のときに 開いているアイは $\eta$ が大になるにつれて閉じ，代わ って $T_{b} / 2$ 離れた時点で別のアイが開いてくるのがわ

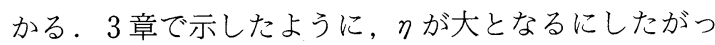
て, 識別点雑音電力は小となることから, $\eta$ が大の場 合のアイを用いて信号検出を行えば誤り率の改善が期 待できる。
図6にアイパターンから求めた $\eta$ とアイ開口率 $\varepsilon$ の関係を示す. ただし， $\beta=0.5, x_{c}=0.01$ としている. 図から $\eta=1.3$ 付近で所望のアイが最も開くことがわ かる. 図 7 に時間軸方向のアイの開口の半分を $T_{b}$ で 規格化した值で定義される夕イミングマージン ${ }^{9} \alpha$ と

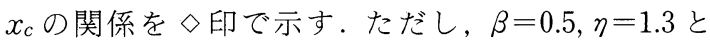
している.また， NRZ 符号に対する積分検出方式 $(\beta$ $=0.5, \eta=1 ）$ の場合も・印で併せて示している. 図に 見られるように，NRZ符号の場合には遮断周波数の 増大に伴って急激に劣化するのに対し, 本方式では劣 化はほとんど見られない. 現実的な值である $x_{c}=$ $0.01^{11}$ に扔いてはほとんど差は見られず，記録波形が ランレングス制限される本方式の方が有利と考えられ る.

\section{5. ビタビ復号器}

図1のハイパスフィルタによる遮断の影響を無視す ると(13)式から, 表 2 に示す状態推移表が得られ る ${ }^{8)}$.さらにこれにより, 図 8 の状態推移と図 9 のト レリス線図を得る。ここで, 各枝に付した值は $a_{k} / b_{k}$

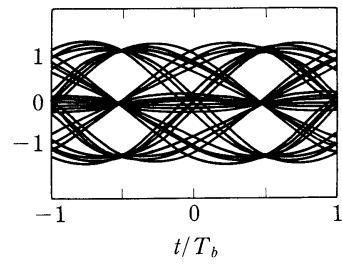

(a) $\eta=0.9$

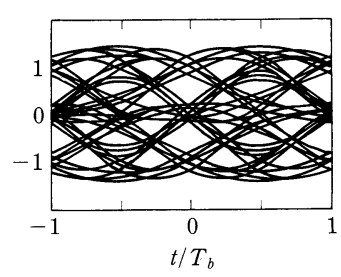

(b) $\eta=1.1$

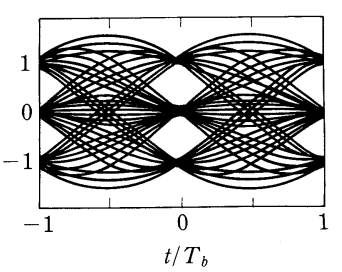

(c) $\eta=1.3$

図 5 アイパターン $\left(\beta=0.5, x_{c}=0.01\right)$

Eye patterns $\left(\beta=0.5, x_{c}=0.01\right)$

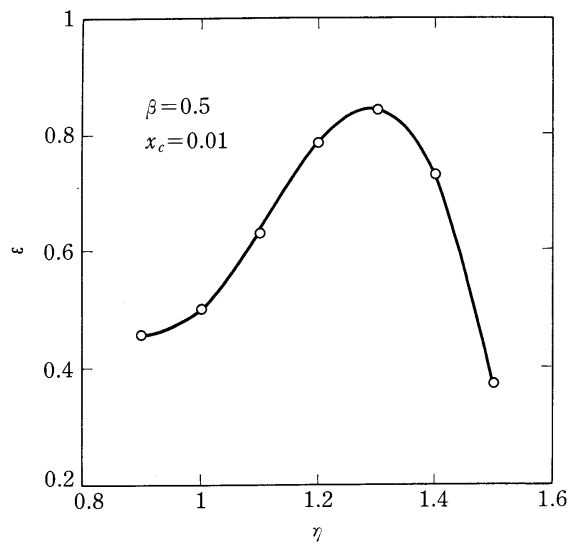

図 6 アイ開口率と $\eta$ の関係 Eye opening vs. $\eta$.

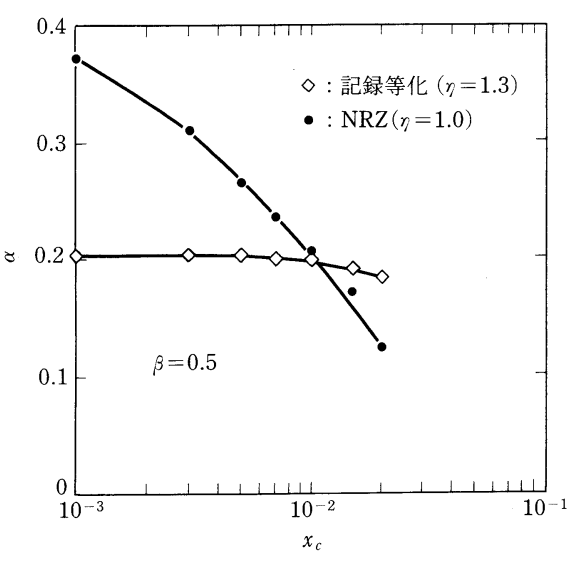

図 7 タイミングマージンと $x_{c}$ の関係 Timing margin vs. $x_{c}$. 
表 2 状態推移表

State transition table.

\begin{tabular}{c|c|c|c|c}
\hline \multicolumn{1}{c}{$a_{k}$} & \multicolumn{3}{|c|}{ 現状態 } & \multicolumn{2}{|c}{$b_{k}$} \\
\cline { 2 - 5 } 前状態 & 1 & 0 & 1 & 0 \\
\hline$S_{0}$ & $S_{1}$ & $S_{2}$ & 0 & 1 \\
\hline$S_{1}$ & $S_{0}$ & $S_{3}$ & 0 & -1 \\
\hline$S_{2}$ & $S_{1}$ & $S_{2}$ & -1 & 0 \\
\hline$S_{3}$ & $S_{0}$ & $S_{3}$ & 1 & 0 \\
\hline
\end{tabular}

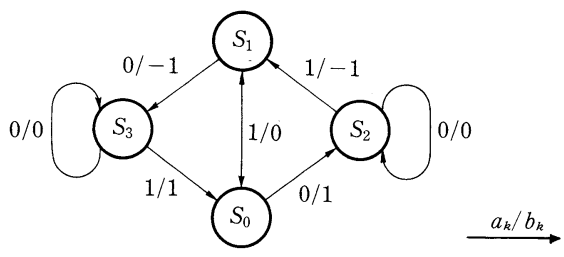

図 8 状態推移図

State transition diagram.

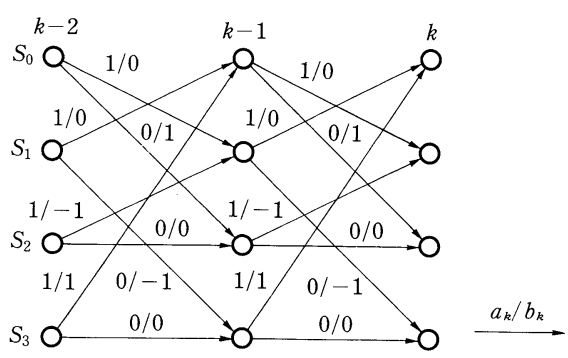

図 9 トレリス線図

Trellis diagram.

を表している。

いま，トレリス線図上の枝の長さを負の対数尤度関 数で表すものとすると ${ }^{12)}$, 時刻 $t=k T_{b}$ における状態 $S_{0}, S_{1}, S_{2}, S_{3}$ に対するメトリックは図 8 より

$$
\left.\begin{array}{l}
m_{k}\left(S_{0}\right)=\min \left\{m_{k-1}\left(S_{1}\right), m_{k-1}\left(S_{3}\right)-y_{k}+0.5\right. \\
m_{k}\left(S_{1}\right)=\min \left\{m_{k-1}\left(S_{0}\right), m_{k-1}\left(S_{2}\right)+y_{k}+0.5\right. \\
m_{k}\left(S_{2}\right)=\min \left\{m_{k-1}\left(S_{0}\right)-y_{k}+0.5, m_{k-1}\left(S_{2}\right)\right\} \\
m_{k}\left(S_{3}\right)=\min \left\{m_{k-1}\left(S_{1}\right)+y_{k}+0.5, m_{k-1}\left(S_{3}\right)\right\}
\end{array}\right\}
$$

となる。ただし， $\left\{y_{k}\right\}$ はビ夕ビ復号器入力系列で,

$$
y_{k}=b_{k}+n_{k}
$$

である.ここで $\left\{n_{k}\right\}$ はビ夕ビ復号器入力雑音系列で, 互いに独立であると仮定している .(23)式に基づくビ 夕ビ復号器は, 文献 12)の復号器を拡張することによ り得ることができる。

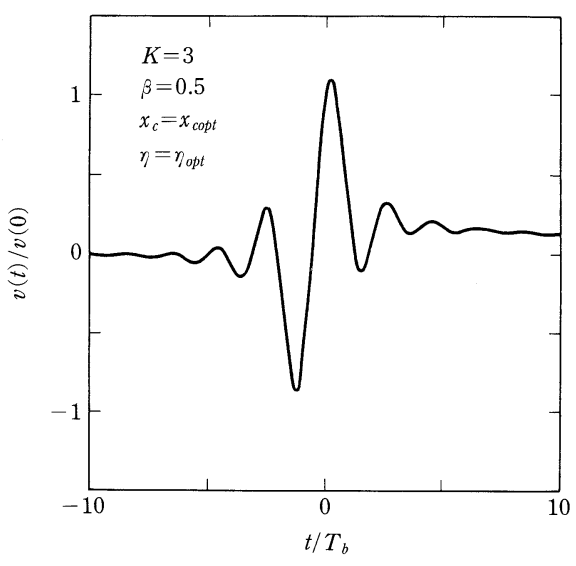

図 10 等化器のインパルス応答 Impulse response function of the equalizer.

\section{6. 誤り率特性}

計算機シミュレーションにより，記録再生等化方式 に対するビタビ復号法のビット誤り率を求め, ビット ごとの復号法と比較する.シミュレーションでは, 入 力データ系列 $\left\{a_{k}\right\}$ として $\mathrm{M}$ 系列を用い, ビ夕ビ復号 器入力データ系列 $\left\{b_{k}\right\}$ は (19) 式を $t=k T_{b}$ でサンプリ ングすることにより得る．ただし，ビットごとの復号 法では再生時の誤り波及を防ぐためにプリコーディン グを施してある ${ }^{8)}$. 5 章ではメトリックの導出にあた り, ビタビ復号器入力に打ける雑音系列を白色ガウス 雑音と仮定した。 しかしながら図 4 に見られるよう に, 実際の雑音系列は白色ではなく有色雑音系列とな る.ビタビ復号法のように信号の相関を利用した復号 法の検討に際して, これを考慮する必要がある。ここ では, 有色雑音系列を, 正規乱数により発生した読出 し点の白色ガウス雑音系列 $\left\{n_{k}^{*}\right\}$ と再生等化器から八 イパスフィルタまでのインパルス応答 $v(t)$ との畳み 込み,

$$
\tilde{n}_{k}=\sum_{i} v\left(i T_{b} / M\right) n_{M \cdot k-i}^{*}
$$

より得た ${ }^{13)}$ 。ここで, $v(t)$ は $(14),(15)$ 式の積のフ ーリ工逆変換により得られ，

$$
\begin{aligned}
v(t)= & \frac{4}{A K \pi} \int_{0}^{(1+\beta) / 2 \eta} \frac{1}{\sin \pi x} e^{\pi K x} R(x) \\
& \frac{\frac{x}{x_{c}} \cos 2 \pi \frac{t}{T_{b}} x+\left(\frac{x}{x_{c}}\right)^{2} \sin 2 \pi \frac{t}{T_{b}} x}{1+\left(\frac{x}{x_{c}}\right)^{2}} d x
\end{aligned}
$$

である.図 10 に $v(t) / v(0)$ を示す。ただし， $K=3, \beta$ $=0.5, \eta=1.3, x_{c}=0.01$ としている. また，(25)式にお 
ける $M$ は $v(t)$ を $T_{b} / M$ 間隔でサンプリングすること を示し， $M$ が大きくなるほど精度が高くなる．（17） 式のフーリエ逆変換と $(16)$ 式の $\sigma^{2}$ の比をとることに より, 有色雑音の相関係数の理論值 $\rho(\lambda)$ を求めるこ とができ，

$$
\begin{aligned}
\rho(\lambda)= & \frac{1}{\sigma^{2}} \cdot \frac{4}{a^{2} K^{2} \pi^{2}} \int_{0}^{(1+\beta) / 2 \eta} \frac{1}{\sin ^{2} \pi x} R(x) e^{2 \pi K x} \\
& \cdot \frac{x^{2}}{x^{2}+x_{c}^{2}} \cos 2 \pi x \lambda / T_{b} \cdot d x
\end{aligned}
$$

となる。図 11 に，条件を図 9 と同一にした場合の $\rho(\lambda)$ と, $M=40$ として $(25)$ 式により発生させた $\left\{\tilde{n}_{k}\right\}$ の相関係数を併せて示す。両者はよく一致しており， シミュレーションで用いた $\left\{\tilde{n}_{k}\right\}$ は所望の有色雑音と なっていることがわかる.したがって, 誤り率シミュ レーションでも $M=40$ としている. また， $\left\{\tilde{n}_{k}\right\}$ の分 散は (16)式の $\sigma^{2}$ に等しくなることから，(25) 式によ

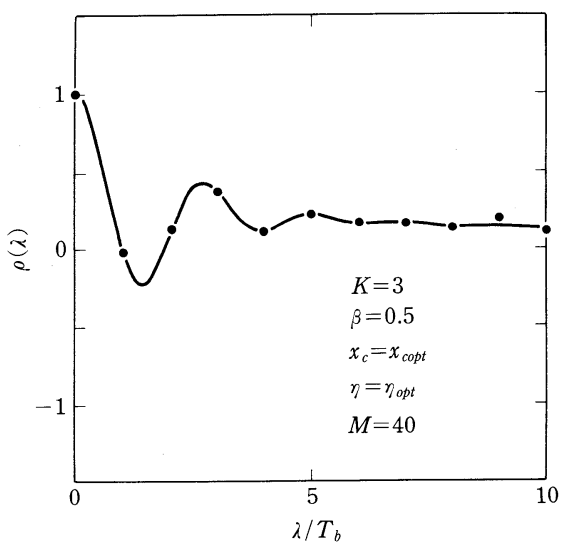

図 11 有色雑音の相関係数

Correlation coefficient of colored noise.

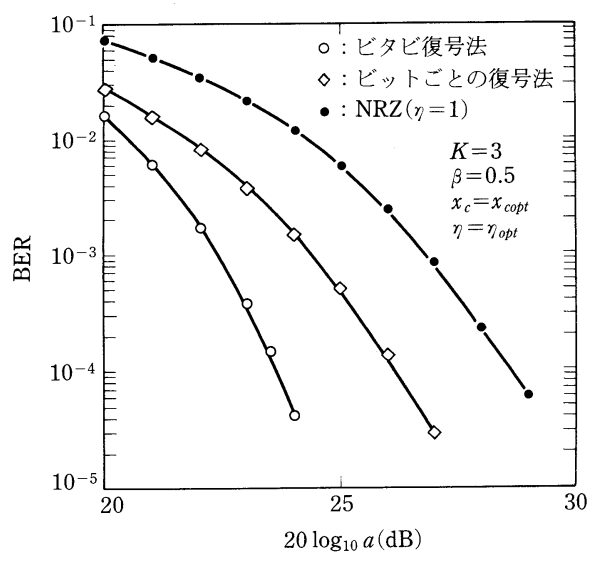

図 12 誤り率特性

BER vs. SNR at the reading point.
り発生させた $\left\{\tilde{n}_{k}\right\}$ の分散を求め，(16)式に適用して 読出し点の SN 比 $a$ を求めている.

図 12 に,ビ夕ビ復号法とビットごとの復号法に対

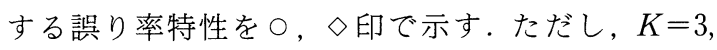
$\beta=0.5, \eta=\eta_{o p t}, x_{c}=x_{c o p t}$ としている.ここで, $\eta_{o p t}$, $x_{\text {copt }}$ は誤り率を最小とするような最適値である.ま た，NRZ 符号に対する積分検出方式の場合の誤り率 も・印で併せて示している.ただし，(23)式における 0.5 ならびにビットごとの復号法, NRZ符号に対す る積分検出方式における閾值は誤り率を最小とするよ うな最適值を選んでいる。図にみられるように，本記 録・再生等化方式にビタビ復号法を適用することによ り $10^{-4}$ の誤り率のときで, ビットごとの復号法の場 合に比べて約 $2.5 \mathrm{~dB} \mathrm{SN}$ 比を改善することができ, $\mathrm{NRZ}$ 符号に対する積分検出方式に対しては約 $4.9 \mathrm{~dB}$ 改善できることがわかる。

\section{7. むす び}

本論文では, 記録波形の DCフリー化が可能で, か つ高い SN 比を達成できる記録・再生等化方式にビ夕 ビ復号法を適用したときの誤り率特性を, 計算機シミ ュレーションにより求めた. シミュレーションに際し ては, 復号器入力雑音として有色雑音を用いた。その 結果, $10^{-4}$ の誤り率において, ビットごとの復号法 に比べ約 $2.5 \mathrm{~dB}$ の SN 比の改善が得られた。また, 従来, 優れた特性を示すことで知られている NRZ 符 号に対する積分検出方式の場合と比較検討した結果, $10^{-4}$ の誤り率において約 $4.9 \mathrm{~dB}$ 改善できることが明 らかとなった。なお，本方式の記録波形は DCフリー 特性を有していることから,ディジタル VTR 等で要 求されるオーバライト特性やアジマス記録の際の隣接 トラックからのクロストーク特性についても優れてい ると考えられる.今後, これらの特性も考慮に入れ て, 種々の等化方式とビタビ復号法を組合せた場合と の性能比較を行う予定である.

日頃有益な御助言をいただく本学 田崎三郎教授と 山田芳郎助教授に深謝いたします。

\section{〔参考 文 献〕}

1) T. D. Howell, D. P. McCown, T. A. Diola, Yawshing Tamg, K. R. Hense and R. L. Gee: "Error Rate Performance of Experimantal Gigabit per Square Inch Recording Components", IEEE Trans. Magn., MAG-26, 5, pp. 2298-2302 (Sep. 1990)

2) M. Suzuki, H. Sawaguchi, H. Takano, Y. Matsuda, F. Kugiya and M. Futamoto: "Read/Write Characteristics of $2 \mathrm{~Gb} / \mathrm{in}^{2}$ Magnetic Recording”, J. Magn. Soc. Jpn., 15, Supp., S 2, pp. 869-874(1991) 
3）田崎, 大沢：“ディジタル磁気記録における信号処理方式”, テレビ誌, 42, 4, pp. 330-337 (Apr. 1985)

4）江藤：“ディジタル記録のための信号処理技術”，テレビ誌， 45, 12, pp. 1511-1514 (Dec. 1991)

5）多田, 今井, 横田 : “小型 HDD, 記録密度「G ビット時代」へ ばく進”, 日経エレクトロニクス, No. 537, pp. 77-106（Sep. 1991)

6) Richard C.Schneider: "Write Equalization in Highlinear-density Magnetic Recording", IBM J. Res. \& Dev. 29, 6, pp. 563-568 (1985)

7) Richard C. Schneider: "Write Equalization for Generalized (d,k) Codes”, IEEE Trans. Magn., MAG-24, 6, pp. 2533-2535 (Nov. 1988)

8）岡本, 大沢, 瀧川, 小野: “記録再生等化における信号検出方 式の一提案”, 信学技報, MR91-19 (Aug. 1991)
9) S. Nakagawa, K. Yokoyama and H. Katayama: "A Study on Detection Method of NRZ Recording”, IEEE Trans., MAG-16, 1, pp. 104-110 (Jan. 1980)

10）江藤, 三田, 平野, 鴻上, 竹下, 桐野: “ 3 值記録, ファイア符号 を用いた試作ディジタル VTR”，テレビ誌，35，7，pp. 563569 (July 1980)

11）梅本, 沢村, 江藤, 片山, 大和田: “ $1.2 \mathrm{~Gb} / \mathrm{s}$ ディジタル VTR の記録再生系の検討”, テレビ誌, 44, 8, pp. 1067-1073 (Aug. 1990)

12) H. Kobayashi : "Application of Probabilistic Decoding to Digital Magnetic Recording Systems”, IBM J. Res. \& Dev., 15, pp. 64-74 (1971)

13) H. Osawa, S. Yamashita and S. Tazaki: "Improvement on Error Rate Performance for FM Recording Code", IEEE Trans. Magn., MAG-27, 6 (Nov. 1991)

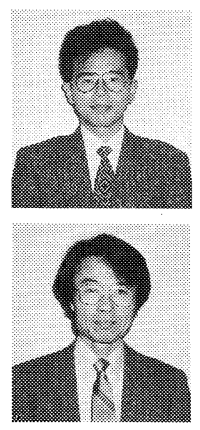

岡本势好弘 昭和 58 年, 愛媛大学工学部 電子工学科卒業. 昭和 60 年, 同大学院修士 課程修了。同年, シャープ(株)に入社. 平成 2 年, 愛媛大学工学部電子工学科助手とな り, 現在に至る。ディジタル記録などの研究 に従事. 正会員.

大势沢势筹昭和 41 年, 大阪大学工学部 通信工学科卒業. 昭和 66 年, 同大学院博士 課程修了. 鉄鋼短大講師, 阪大助手, 愛媛大 助教授を経て, 平成元年, 同大教授. 相関検 波, 光エレクトロニクス, ディジタル記録に 関する研究に従事. 工学博士. 正会員.

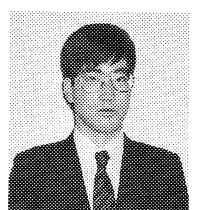

瀧川吉川呰 平成 3 年, 愛媛大学工学部電 子工学科卒業. 現在, 同大学院修士課程在学 中. ディジタル磁気記録における信号処理方 式に関する研究に従事. 学生会員.

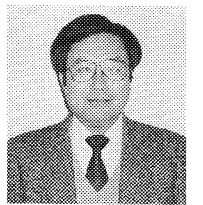

小野 和雄 昭和 45 年, 大阪府立大学工 学部電子工学科卒業. 昭和 47 年, 同大学院 修士課程修了. 同年, 愛媛大学助手. 助教授 を経て, 平成 4 年, 同大学教授. 光エレクト ロニクス, ディジタル記録などの研究に従 事. 工学博士. 